
Not for reproduction, distribution or commercial use.

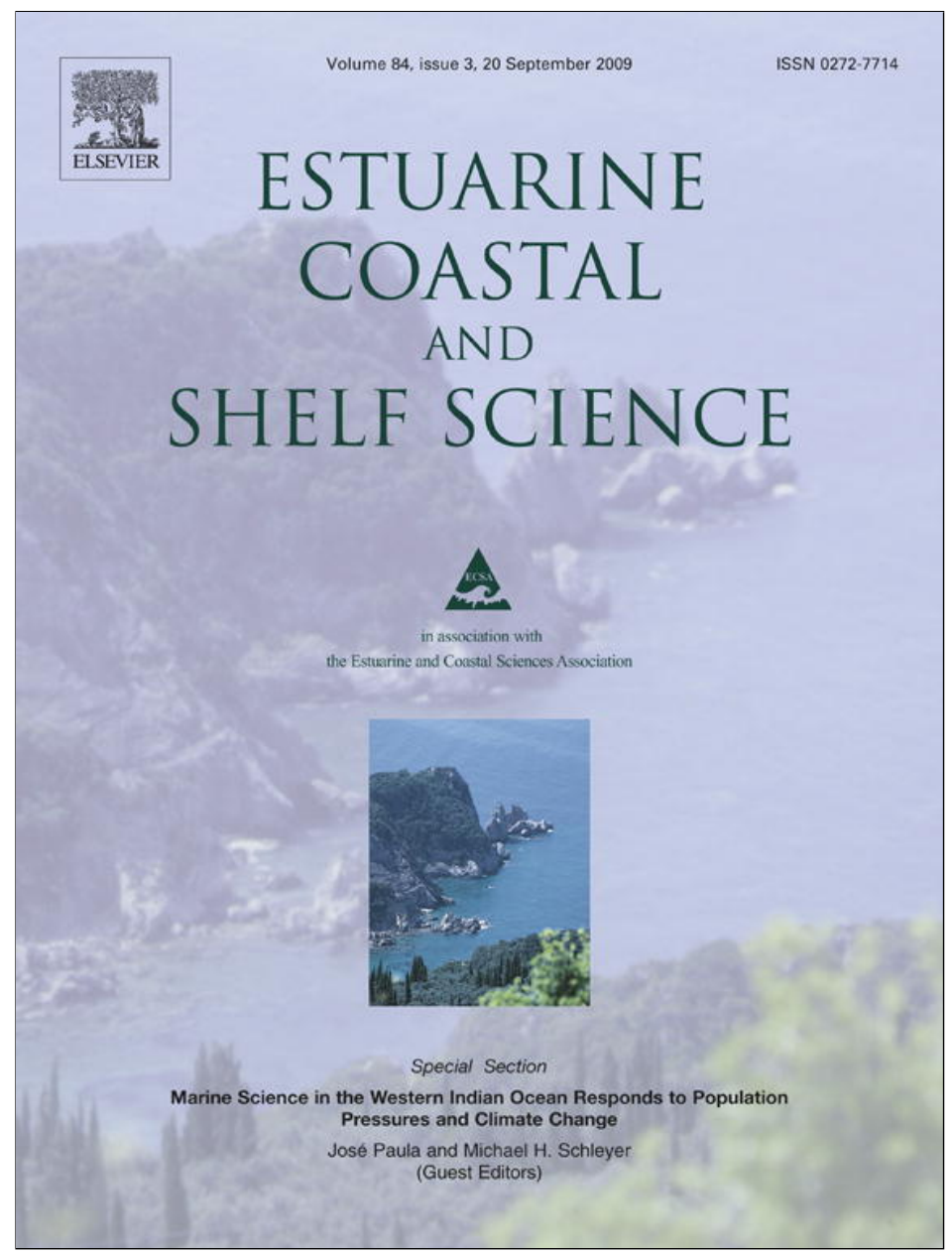

This article appeared in a journal published by Elsevier. The attached copy is furnished to the author for internal non-commercial research and education use, including for instruction at the authors institution and sharing with colleagues.

Other uses, including reproduction and distribution, or selling or licensing copies, or posting to personal, institutional or third party websites are prohibited.

In most cases authors are permitted to post their version of the article (e.g. in Word or Tex form) to their personal website or institutional repository. Authors requiring further information regarding Elsevier's archiving and manuscript policies are encouraged to visit:

http://www.elsevier.com/copyright 


\title{
Population structure, density and food sources of Terebralia palustris (Potamididae: Gastropoda) in a low intertidal Avicennia marina mangrove stand (Inhaca Island, Mozambique)
}

\author{
Gil Penha-Lopes ${ }^{\mathrm{a}, \mathrm{b}, *}$, Steven Bouillon ${ }^{\mathrm{b}, \mathrm{c}, 1}$, Perrine Mangion ${ }^{\mathrm{b}, 2}$, Adriano Macia ${ }^{\mathrm{d}, 3}$, José Paula ${ }^{\mathrm{a}, 4}$ \\ ${ }^{a}$ Centro de Oceanografia, Laboratório Marítimo da Guia, Faculdade de Ciências da Universidade de Lisboa, Avenida Nossa Senhora do Cabo, 939, 2750-642 Cascais, Portugal \\ ${ }^{\mathrm{b}}$ Department of Analytical and Environmental Chemistry, Vrije Universiteit Brussel, Brussels, Belgium \\ ${ }^{\mathrm{c}}$ Katholieke Universiteit Leuven, Department of Earth and Environenmental Sciences, Kasteelpark Arenberg 20, B-3001 Leuven, Belgium \\ ${ }^{\mathrm{d}}$ Departamento de Ciências Biológicas, Faculdade de Ciências, Universidade Eduardo Mondlane, C.P. 257 Maputo, Mozambique
}

\section{A R T I C L E I N F O}

\section{Article history:}

Received 6 March 2008

Accepted 15 April 2009

Available online 3 May 2009

\section{Keywords:}

Terebralia palustris

population structure

distribution

feeding

stable isotopes

mangroves

\begin{abstract}
A B S T R A C T
Population structure and distribution of Terebralia palustris were compared with the environmental parameters within microhabitats in a monospecific stand of Avicennia marina in southern Mozambique. Stable carbon and nitrogen isotope analyses of $T$. palustris and potential food sources (leaves, pneumatophore epiphytes, and surface sediments) were examined to establish the feeding preferences of T. palustris. Stable isotope signatures of individuals of different size classes and from different microhabitats were compared with local food sources. Samples of surface sediments $2.5-10 \mathrm{~m}$ apart showed some variation $\left(-21.2 \%\right.$ to $-23.0 \%$ ) in $\delta^{13} \mathrm{C}$, probably due to different contributions from seagrasses, microalgae and mangrove leaves, while $\delta^{15} \mathrm{~N}$ values varied between $8.7 \%$ and $15.8 \%$, indicating that there is a very high variability within a small-scale microcosm. Stable isotope signatures differed significantly between the T. palustris size classes and between individuals of the same size class, collected in different microhabitats. Results also suggested that smaller individuals feed on sediment, selecting mainly benthic microalgae, while larger individuals feed on sediment, epiphytes and mangrove leaves. Correlations were found between environmental parameters and gastropod population structure and distribution vs. the feeding preferences of individuals of different size classes and in different microhabitats. While organic content and the abundance of leaves were parameters that correlated best with the total density of gastropods ( $>85 \%)$, the abundance of pneumatophores and leaves, as well as grain size, correlated better with the gastropod size distribution $(>65 \%)$. Young individuals (height $<3 \mathrm{~cm}$ ) occur predominantly in microhabitats characterized by a low density of leaf litter and pneumatophores, reduced organic matter and larger grain size, these being characteristic of lower intertidal open areas that favour benthic microalgal growth. With increasing shell height, T. palustris individuals start occupying microhabitats nearer the mangrove trees characterized by large densities of pneumatophores and litter, as well as sediments of smaller grain size, leading to higher organic matter availability in the sediment. (c) 2009 Published by Elsevier Ltd.
\end{abstract}

\footnotetext{
* Corresponding author. Centro de Oceanografia, Laboratório Marítimo da Guia, Faculdade de Ciências da Universidade de Lisboa, Avenida Nossa Senhora do Cabo 939, 2750-642 Cascais, Portugal.

E-mail addresses: gil.penha-lopes@fc.ul.pt (G. Penha-Lopes), steven.bouillon@ ees.kuleuven.be (S. Bouillon), pmangion@vub.ac.be (P. Mangion), adriano@ zebra.uem.mz (A. Macia), jppaula@fc.ul.pt (J. Paula).

1 Tel.: +32 498513608 .

2 Tel.: +3226293968 .

3 Tel.: +258823133680 .

4 Tel.: +351214869211.
}

\section{Introduction}

Mangrove systems represent complex and highly dynamic environments in which faunal assemblages typically occupy distinct horizontal or vertical zones, and manifest complex temporal patterns in their activities (Robertson and Alongi, 1992; Hogarth, 2007). Although biological, chemical and physical properties are expected to be reflected in strong correlations between benthic fauna and sedimentary properties, most studies have shown these relationships to be relatively weak (e.g., Chapman and Tolhurst, 2007). The crucial role of marine invertebrates in the food web, nutrient cycling and overall energy flux in Indo-Pacific mangrove ecosystems has become a standard paradigm in 
ecological research on these tidal forests (Bouillon et al., 2008). Recently, evidence is emerging that many invertebrates have a small home-range and derive most of their diet from locally available food sources (Guest et al., 2006). Small-scale changes in their stable isotope signatures (derived from the carbon and nitrogen sources of their diet) may be a useful tool to track and explain invertebrate microdistribution patterns (Guest and Connolly, 2004; Guest et al., 2004).

During the last decade, one of the most common and abundant mangrove gastropods, Terebralia palustris (Linnaeus), has been the subject of several ecological studies due to the significant quantities of leaf litter that it consumes and processes, and it has become a recognized link in nutrient cycling in mangrove forests (Slim et al., 1997; Fratini et al., 2004). It is found in substrata that range from mud to sand, and extends from the upper Avicennia marina belt down to the lower fringe stands (Rambabu et al., 1987; Fratini et al., 2004). Terebralia palustris is known to be omnivorous, feeding on detritus, leaf litter, mangrove propagules, carrion, sediment particles, benthic diatoms and bacteria (Nishihira, 1983; Rambabu et al., 1987; Dahdouh-Guebas et al., 1998; Fratini et al., 2000).

A spatial separation between young and older individuals was first observed by Soemodihardjo and Kastoro (1977). Due to anatomical differences in the structure of the radula, only large (shell height $>5 \mathrm{~cm}$ ) Terebralia palustris actively feed on fallen mangrove leaves, propagules and fruits, while small individuals (shell height $<5 \mathrm{~cm}$ ) are usually detritivorous or deposit feeders (Nishihira, 1983; Houbrik, 1991; Slim et al., 1997; Dahdouh-Guebas et al., 1998; Fratini et al., 2004; Pape et al., 2008). This different feeding strategy has been used to explain the spatial segregation between juveniles (more common in tidal channels and pools) and adults (common in the forest) reported by various authors for Jakarta (Soemodihardjo and Kastoro, 1977), Western Australia (Wells, 1980) and Gazi Bay, Kenya (Slim et al., 1997; Pape et al., 2008). In contrast, some other studies have shown no spatial separation between juveniles and adults (e.g., Fratini et al., 2004 for Gazi Bay, Kenya). Only Pape et al. (2008) have attempted to elucidate the population structure or distribution of $T$. palustris relative to environmental variables and stable isotopic composition. Their study was undertaken along two transects from the landward mudflat zone to the seaward seagrass zone (passing through the mangrove forest), with sampling intervals of $8 \mathrm{~m}$.

The present study aimed to elucidate Terebralia palustris microdistribution, as well as its feeding strategies, at spatial scales of $1.25-2.50 \mathrm{~m}$. Its spatial distribution and population structure were compared with important abiotic and biotic parameters, such as organic matter content, sediment granulometry, leaf litter and pneumatophore abundance. Together with the environmental parameters, foot muscle and potential food sources of $T$. palustris were subjected to stable isotope analysis (carbon and nitrogen) to better elucidate the relationship between gastropod feeding strategy and distribution. The variability in stable isotope signatures of the sediments and different size classes of $T$. palustris were also documented in each microhabitat.

\section{Materials and methods}

\subsection{Study site}

Inhaca is a small island $\left(42 \mathrm{~km}^{2}\right)$ situated $32 \mathrm{~km}$ off Maputo in southern Mozambique, East Africa $\left(26^{\circ} \mathrm{S} 33^{\circ} \mathrm{E}\right)$. The east coast is exposed to the Indian Ocean, whereas the western and southern coasts face Maputo bay. The island is positioned in a transitional region of tropical to warm subtropical conditions and constitutes a barrier between Maputo Bay and the Indian Ocean. The climate of
Inhaca island is characterized by hot and wet (September-March) and warm and dry (April-September) seasons (Bandeira, 1995).

In August 2006, this study was conducted in the low intertidal Avicennia marina belt in the Saco mangrove during a spring low tide. The Saco bay is located at the southern end of Inhaca Island, occupies an area of 204 ha, and is bordered by mangroves. While Ceriops tagal, Bruguiera gymnorrhiza and Rhizophora mucronata are found along the channels and in the most densely forest areas, A. marina covers the upper and lower limits of the mangrove (Kalk, 1995; De Boer, 2000). The subtidal zone is characterized by patches of seagrasses (Kalk, 1995). At the seaward edge, the A. marina trees are large, often more than $5 \mathrm{~m}$ high, and their pneumatophores can extend to several meters around the trunk (Kalk, 1995). In this lower A. marina belt, three areas were randomly selected and, in each of these, four pneumatophore zones were studied (Fig. 1).

Lower - lower half of the pneumatophore zone (over half a pneumatophore zone away from the Avicennia marina canopy).

Mid - central pneumatophore zone.

Upper - upper half of the pneumatophore zone (the latter two zones comprising equal divisions of under half a pneumatophore zone from the Avicennia marina canopy).

Canopy - under the Avicennia marina canopy.

Each of the pneumatophore zones (excluding the Canopy) comprised a belt that was between 5 and $10 \mathrm{~m}$ long and an average of $5 \mathrm{~m}$ wide (see Fig. 1 for clarification). An Inter-pneumatophore zone was similarly delineated between pneumatophore zones corresponding to the area adjacent to the Upper and Canopy regions of the pneumatophore zones (see Fig. 1).

\subsection{Population structure}

Four quadrats of $0.25 \mathrm{~m}^{2}$ were randomly allocated in each of the pneumatophore and inter-pneumatophore zones. All Terebralia palustris specimens inside the quadrats were collected (including those with more than $50 \%$ of the body inside the quadrat) and stored in a cool box. In the laboratory, they were counted, weighed (wet weight) and their height (shell height - SH - maximum linear dimension of the shell from the apex to the anterior edge of the lip) was measured.

\subsection{Environmental data}

While some biogeochemistry parameters are known to be relatively constant throughout the year, or oscillate seasonally or with important events (e.g., heavy rains or winds), some fluctuate significantly during a single tidal cycle (e.g., temperature, salinity) (e.g., Chapman and Tolhurst, 2007). Only parameters more or less consistent within a tidal cycle were thus measured in this study, providing a realistic explanation of the observed population structure and distribution patterns.

\subsubsection{Pneumatophore and leaf density}

The number of pneumatophores (protruding $>0.5 \mathrm{~cm}$ above the sediment) and leaves were counted in each quadrat.

\subsubsection{Granulometry}

Two sediment cores ( $3 \mathrm{~cm} \varnothing$ and $2 \mathrm{~cm}$ depth) were extracted per quadrat. Each core was stored in a plastic vial and stored in a cool box during transport to the laboratory. There the sediment samples were oven-dried at $105^{\circ} \mathrm{C}$ to constant weight. The different sediment particle sizes were separated on a mechanical shaker using a series of sieves ranging from $2 \mathrm{~mm}$ upwards and graded following the Wentworth scale. The residues in each sieve were weighed and assigned to a textural group according to Folk (1954). The median grain size of each sample and the textural group 
A

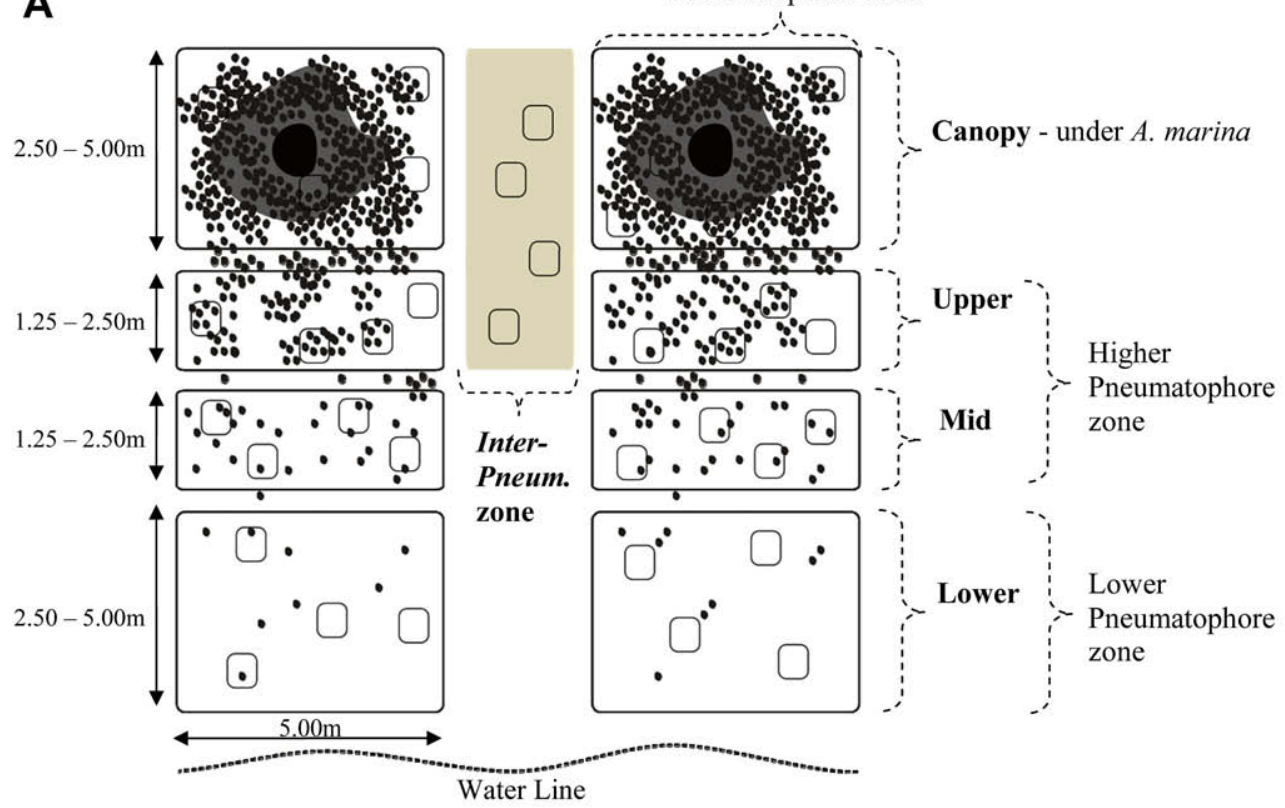

B

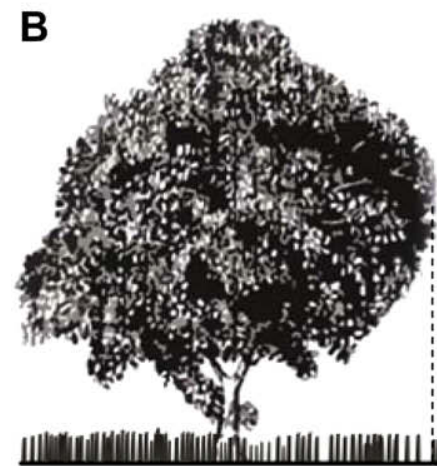

Pneumatophore Zone

(Lateral view)
Pneumatophore zone

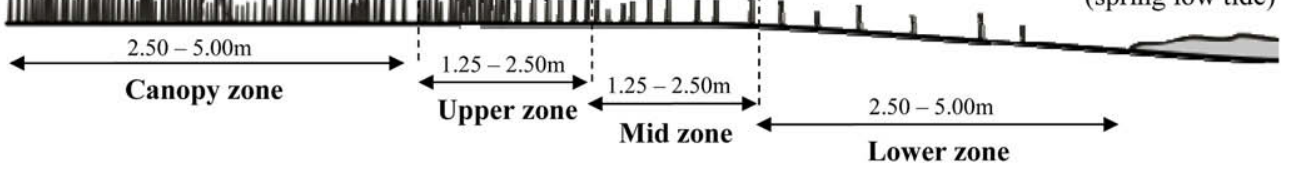

Fig. 1. Zonation in the lower Avicennia marina belt in the Saco, Inhaca Island, southern Mozambique, during low tide. (A) Top view of two pneumatophore zones, where Canopy, Upper, Mid and Lower sampling zones are shown as rectangular areas $1.25-5.00 \mathrm{~m}$ long and $5 \mathrm{~m}$ wide. An Inter-pneumatophore zone (grey zone) is also shown. Small black dots designate pneumatophores $(\bullet)$ and small squares sample quadrats of $0.25 \mathrm{~m}^{-2}(\square)$. (B) Lateral view of a pneumatophore zone.

in each zone (derived from 24 replicates from each of the three study areas) was determined using Gradistat 5 software (Blott and Pye, 2001).

\subsubsection{Organic content}

Each sediment core was stored in a cool box during transport to the laboratory. There the samples were dried at $105^{\circ} \mathrm{C}$ to a constant weight, ignited at $550{ }^{\circ} \mathrm{C}$ for three hours and cooled in a desiccator. The loss on ignition (LOI) was measured and the organic content expressed as a percentage of the dry weight (Heiri et al., 2001).

\subsection{Stable isotopes}

\subsubsection{Terebralia palustris}

Whenever possible, five (or more) individuals of each size class $(\mathrm{SH}<3,3<\mathrm{SH}<5$ and $\mathrm{SH}>5 \mathrm{~cm})$ per zone were washed with distilled water and part of the foot muscle was removed and dried at $60^{\circ} \mathrm{C}$ for $72 \mathrm{~h}$. After drying, the samples were frozen until further processing for stable isotope analysis.

\subsubsection{Sediment, leaves and pneumatophore epiphytes}

Two sediment cores ( $3 \mathrm{~cm} \varnothing$ and $2 \mathrm{~cm}$ depth) were collected in each zone. As the isotopic signature of mangrove leaves generally does not change significantly with decomposition (Zieman et al., 1984; Dehairs et al., 2000), at least five mangrove leaves of all the species present (Avicennia marina, Rhizophora mucronata and Ceriops tagal) were randomly picked from different trees in or just around the study area. Pneumatophore epiphytes were gently scraped off with surgical blades. These scrapings were randomly taken from within the range occupied by Terebralia palustris. Sediment, leaves and epiphytes were transport to the laboratory in a cool box. Leaves and epiphytes were subsequently washed with distilled water, and dried at $60^{\circ} \mathrm{C}$ for $72 \mathrm{~h}$, while the sediment samples were freeze-dried.

\subsubsection{Analytical procedures}

All samples were ground to a fine powder and subsamples of the sediment and epiphytes were acidified with dilute (5\%) $\mathrm{HCl}$ before analysis to remove carbonates. $\delta^{13} \mathrm{C}$ and $\delta^{15} \mathrm{~N}$ analyses were performed with a ThermoFinnigan Flash1112 elemental analyzer, 
coupled to a ThermoFinnigan delta $+\mathrm{XL}$ via a Conflo III interface, with a typical reproducibility of $\pm 0.15 \%$ for both $\delta^{13} \mathrm{C}$ and $\delta^{15} \mathrm{~N}$. All stable isotope ratios are expressed relative to the conventional standards (VPDB limestone for carbon and atmospheric $\mathrm{N}_{2}$ for nitrogen) as $\delta$ values, defined as:

$\delta^{13} \mathrm{C}=\frac{X_{\text {sample }}-X_{\text {standard }}}{X_{\text {standard }}} \times 10^{3}[\%$ oo $]$

where $X={ }^{13} \mathrm{C} /{ }^{12} \mathrm{C}$ or ${ }^{15} \mathrm{~N} /{ }^{14} \mathrm{~N}$ in the case of $\delta^{15} \mathrm{~N}$.

\subsection{Statistical analyses}

Stable isotope signatures of all samples (sediment, leaves and epiphytes) and between Terebralia palustris of different size classes and zones were compared using non-parametric tests (KruskalWallis), followed by a Dunn multicomparisons test whenever statistical significances were found. Principal component analysis (PCA) was used to reduce the multidimensional environmental data sets to lower dimensions. The variables used in the PCA were percent organic matter, granulometry, number of leaves and pneumatophores per quadrat. Analysis of similarities (ANOSIM) has been widely used for testing hypotheses on spatial differences and temporal changes in biological assemblages (Clarke and Gorley, 2006). This test was used to separate zones by analysing each of the following data sets separately: (1) population data (T. palustris density and average height); and (2) environmental data (\% organic matter, granulometry, number of leaves and pneumatophores per quadrat). The link between environmental variables and T. palustris' distribution and abundance was analysed using the BEST analysis. This test maximises the rank correlation between the resemblance matrices of the environmental (percent organic matter, abundance of leaves and pneumatophores, and average grain size) and community variables (average shell length and average density), where all permutations of the variables are tried in the BIOENV algorithms (Clarke and Gorley, 2006). Prior to the PCA, ANOSIM and BEST analyses, environmental data were $\log (x+1)$-transformed (for PCA and ANOSIM) or $\log (x)$-transformed (for BEST) and normalized, while T. palustris population data were square roottransformed. Although ANOSIM compares zones with all variables, for a more detailed analysis of each environmental or population variable, non-parametric tests (Kruskal-Wallis) were used followed by Dunn's test whenever differences were detected using the Kruskal-Wallis test. Kruskal-Wallis and Dunn tests were performed using GraphPad Instat, while PCA, ANOSIM and BEST analyses were performed using Primer 6 software.

\section{Results}

\subsection{Environmental factors}

Environmental variables were significantly different between zones (Table 1). When analysed with ANOSIM (Table 2), there was a clear separation between all the five zones, defined a priori (Global $R=0.65$ ). All the pairwise tests between the zones manifested significant differences between them, although some zones were found to overlap (Lower vs. Mid, and Mid vs. Upper). With the help of PCA (Fig. 2), it was possible to reduce all the environmental data sets to two principal components, which explained more than $77 \%$ of the cumulative percentage variation (PC1, 50\% and PC2, 27\%). The Canopy and Upper zone data are found more frequently on the negative side of the PC1 axis, where the number of leaves, pneumatophores and sediment organic matter are higher and the mean grain size is smaller. The Lower and Inter-pneumatophore zones are clearly located at the positive side of the axis, while the Mid zone attained both negative and positive values. In the PC2, negative values are related to an increase in medium grain size and the number of pneumatophores, and a decrease in sediment organic matter. This axis clearly separates the Inter-pneumatophore zone from all the other zones (Fig. 2). Using Gradistat 5, the Lower and Mid zones were classified as "sandy gravel", the Upper and Interpneumatophore zones as "muddy sand" and the Canopy zone as "gravelly mud".

\subsection{Stable isotope analysis}

\subsubsection{Primary producers}

The mean carbon stable isotope ratio of Avicennia marina $(-28.8 \pm 0.5 \%)$ was significantly lower than the values obtained for Rhizophora mucronata $(-27.5 \pm 0.5 \%)$ and Ceriops tagal $(-27.2 \pm 0.3 \%$ ) (Fig. 3). The nitrogen stable isotope ratios manifested the opposite trend with much higher values in $A$. marina $(7.1 \pm 1.2 \%)$ compared to $R$. mucronata and $C$. tagal $(0.9 \pm 0.3$ and $1.4 \pm 0.5 \%$, respectively) (Fig. 3). The carbon stable isotope ratios of epiphytes $(-24.1 \pm 1.1 \%$ o scraped off the pneumatophores were more enriched than those of the mangrove leaves and their $\delta^{15} \mathrm{~N}$ signatures were rather low $(1.3 \pm 0.3 \%$ ) (Fig. 3 ).

\subsubsection{Sediment}

The sediment $\delta^{13} \mathrm{C}$ signatures $(-22.2 \pm 0.7 \%$ ) were generally enriched compared to mangrove leaf tissue (approximately $-28 \%$ ) (Fig. 5). However, sediment from the different zones manifested some significant differences regarding their $\delta^{15} \mathrm{~N}$ and $\mathrm{C} / \mathrm{N}$ ratios (Table 3). From the Canopy down to the lower pneumatophore zone, there was a slight increase in the sediment $\delta^{13} \mathrm{C}$ signatures (going from -22.6 to $-21.2 \%$ ), whereas the $\mathrm{C} / \mathrm{N}$ ratios remained more or less constant along this transect $(\sim 14 \pm 0.5$, Table 3$)$. In contrast, sediment from the Inter-pneumatophore zone differed from that in the Pneumatophore zone, having $\delta^{13} \mathrm{C}$ even more depleted than in the Canopy zone and a greater $\mathrm{C} / \mathrm{N}$ ratio. Although sedimentary $\delta^{15} \mathrm{~N}$ values became enriched from the Canopy towards the Lower zone (from $8.7 \%$ to $15.8 \%$ ), the high variability masked any clear trend. Average $\delta^{13} \mathrm{C}$ and $\delta^{15} \mathrm{~N}$ values in the Interpneumatophore zone were similar to those found in Mid and Upper zones.

\section{Table 1}

Average $( \pm$ SD) pneumatophore and leaf density, sediment median grain size, percentage of sediment organic matter (LOI), Terebralia palustris height, density and total biomass recorded in each of the five study zones. Different letters indicate a significant difference $(p<0.05)$ between the five zones for each variable. (Numbers in parentheses indicate numbers of replicates).

\begin{tabular}{|c|c|c|c|c|c|c|c|}
\hline \multirow[t]{2}{*}{ Zone } & \multicolumn{4}{|l|}{ Local properties } & \multicolumn{3}{|c|}{ Terebralia palustris } \\
\hline & $\begin{array}{l}\text { Pneumatophore } \\
\text { density }\left(\mathrm{m}^{-2}\right)\end{array}$ & Leaf density $\left(\mathrm{m}^{-2}\right)$ & Median grain size $(\mathrm{mm})$ & LOI (\% org. mat) & Height $(\mathrm{cm})$ & Density (ind $\mathrm{m}^{-2}$ ) & $\begin{array}{l}\text { Biomass (wet weight) } \\
\left(\mathrm{g} \mathrm{m}^{-2}\right)\end{array}$ \\
\hline Inter-pneumatophore & $2.3 \pm 5.5^{\mathrm{a}}(12)$ & $23.7 \pm 68.5^{\mathrm{a}}(12)$ & $1.3 \pm 0.2^{\mathrm{a}, \mathrm{b}}(12)$ & $2.7 \pm 2.5^{\mathrm{a}, \mathrm{b}}(8)$ & $2.3 \pm 0.8^{\mathrm{a}}(551)$ & $182.7 \pm 224.5^{\mathrm{b}, \mathrm{c}}(12)$ & $44.05 \pm 58.44^{\mathrm{b}}(12)$ \\
\hline Lower & $64.7 \pm 28.5^{\mathrm{b}}(12)$ & $2.7 \pm 3.9^{\mathrm{a}}(12)$ & $1.4 \pm 0.4^{\mathrm{a}}(12)$ & $1.6 \pm 0.4^{\mathrm{a}}(8)$ & $2.8 \pm 1.3^{\mathrm{a}, \mathrm{b}, \mathrm{c}}(7)$ & $2.3 \pm 4.7^{\mathrm{a}}(12)$ & $0.85 \pm 1.56^{\mathrm{a}}(12)$ \\
\hline Mid & $85.0 \pm 37.3^{b, c}(12)$ & $8.7 \pm 7.2^{\mathrm{a}, \mathrm{b}}(12)$ & $1.4 \pm 0.3^{a}(12)$ & $3.4 \pm 3.1^{\mathrm{a}, \mathrm{b}}(8)$ & $2.6 \pm 0.8^{\mathrm{b}}(582)$ & $193.7 \pm 159.3^{\mathrm{c}}(12)$ & $62.42 \pm 39.65^{\mathrm{b}}(12)$ \\
\hline Upper & $256.3 \pm 77.6^{\mathrm{c}, \mathrm{d}}(12)$ & $37.3 \pm 27.4^{\mathrm{b}, \mathrm{c}}(12)$ & $0.9 \pm 0.4^{\mathrm{b}, \mathrm{c}}(12)$ & $3.1 \pm 1.5^{\mathrm{a}, \mathrm{b}}(8)$ & $3.8 \pm 1.1^{\mathrm{c}}(383)$ & $127.7 \pm 81.0^{c}(12)$ & $114.26 \pm 46.96^{\mathrm{c}}(12)$ \\
\hline Canopy & $398.0 \pm 142.0^{\mathrm{d}}(12)$ & $140.7 \pm 99.4^{\mathrm{c}}(12)$ & $0.8 \pm 0.2^{c}(12)$ & $5.0 \pm 1.3^{\mathrm{b}}(8)$ & $4.7 \pm 0.6^{\mathrm{d}}(86)$ & $29.0 \pm 39.9^{\mathrm{a}, \mathrm{b}}(12)$ & $46.42 \pm 62.36^{\mathrm{a}, \mathrm{b}}(12)$ \\
\hline
\end{tabular}


Table 2

Results of ANOSIM global and pair-wise tests using Euclidean distance (for environmental) or Bray-Curtis similarity (for population data), when comparing between study zones: environmental data (\% organic matter content; median grain size; number of leaves and pneumatophores per quadrat); and population data ( $T$. palustris density and average height). $R$-values $>0.75$ were interpreted as wellseparated; $R>0.5$ as overlapping but clearly different, and $R<0.25$ as not separable.

\begin{tabular}{lll}
\hline Pair-wise & $\begin{array}{l}\text { Environmental data, } \\
\text { Global } R=0.65 \\
(p=0.001)\end{array}$ & $\begin{array}{l}\text { Population data, } \\
\text { Global } R=0.26 \\
(p=0.001)\end{array}$ \\
\hline Lower vs. Mid & $R=0.176(p=0.009)$ & $R=0.077(p=0.002)$ \\
Lower vs. Upper & $R=0.822(p=0.001)$ & $R=0.768(p=0.001)$ \\
Lower vs. Canopy & $R=0.997(p=0.001)$ & $R=0.203(p=0.041)$ \\
Lower vs. Inter-pneumatophore & $R=0.453(p=0.002)$ & $R=0.542(p=0.002)$ \\
Mid vs. Upper & $R=0.218(p=0.012)$ & $R=0.007(p=0.847)$ \\
Mid vs. Canopy & $R=0.800(p=0.001)$ & $R=0.017(p=0.017)$ \\
Mid vs. Inter-pneumatophore & $R=0.500(p=0.001)$ & $R=0.041(p=0.701)$ \\
Upper vs. Canopy & $R=0.902(p=0.001)$ & $R=0.131(p=0.043)$ \\
Upper vs. Inter-pneumatophore & $R=0.830(p=0.001)$ & $R=0.022(p=0.517)$ \\
Canopy vs. Inter-pneumatophore & $R=0.936(p=0.001)$ & $R=0.058(p=0.142)$ \\
\hline
\end{tabular}

\subsubsection{Terebralia palustris}

Stable isotope signatures in T. palustris individuals changed according to individual size, as well as to the zone they inhabited. Irrespective of the sampling zone, the overall picture was that, with increasing animal size, $\delta^{13} \mathrm{C}$ values tended to decrease but the $\delta^{15} \mathrm{~N}$ values were more irregular (Table 3, Fig. 5 ). The $\delta^{13} \mathrm{C}$ signatures of individuals larger than $5 \mathrm{~cm}$ was significantly different $(p<0.001)$ from smaller size classes $(-20.1 \pm 0.8 \%,-19.9 \pm 0.8 \%$ and $-21.3 \pm 0.9 \%$ for size classes $<3,3-5$ and $>5 \mathrm{~cm}$, respectively) (Table 4). Small individuals $(<3 \mathrm{~cm})$ collected in the Mid zone were significantly $(p<0.001)$ depleted in $\delta^{13} \mathrm{C}$ when compared to the ones collected in the Upper and Inter-pneumatophore zones, while individuals $3-5 \mathrm{~cm}$ in height were significantly $(p<0.001)$ enriched in the Inter-pneumatophore zone relative to those found in the Mid and Upper zones. The $\delta^{15} \mathrm{~N}$ signature of small T. palustris was significantly enriched in the Upper zone when compared to the individuals collected in the Mid $(p<0.05)$ and Inter-pneumatophore $(p<0.001)$ zones, while mid-size individuals inhabiting the Inter-pneumatophore zone were significantly enriched relative to those found in the Canopy zone $(p<0.05)$ (Fig. 4$)$.

\subsection{Population distribution and structure}

A clear pattern was found in Terebralia palustris microscale distribution (Fig. 5). In the Lower zone, none or very few individuals were found (Table 1). The smallest animals occurred predominantly in the Inter-pneumatophore and Mid zones, where the highest densities of T. palustris were observed. Small to large individuals were collected in the Upper zone, although the latter at much higher densities, while only larger individuals were observed in the Canopy zone. There was a significant increase in size in T. palustris from the Mid zone towards the Canopy zone (Table 1). Although the mean biomass (wet weight) mirrored the average density, the former is strongly influenced by the average size, resulting in a very low biomass in the Lower zone and very high in the Upper zone (Table 1).

ANOSIM analysis (Table 2) indicated that the zones were barely separable with regard to both Terebralia palustris density and average size (Global $R=0.26$ ). However, the pairwise tests indicated that the Lower zone was significantly different from all the other zones $(p<0.041)$, as was the Canopy zone from the Mid $(p<0.041)$ and Upper $(p<0.041)$ zones, but they were barely separable $(R<0.25)$. All the other pairwise comparisons overlapped and were not significantly different from each other (Table 2).

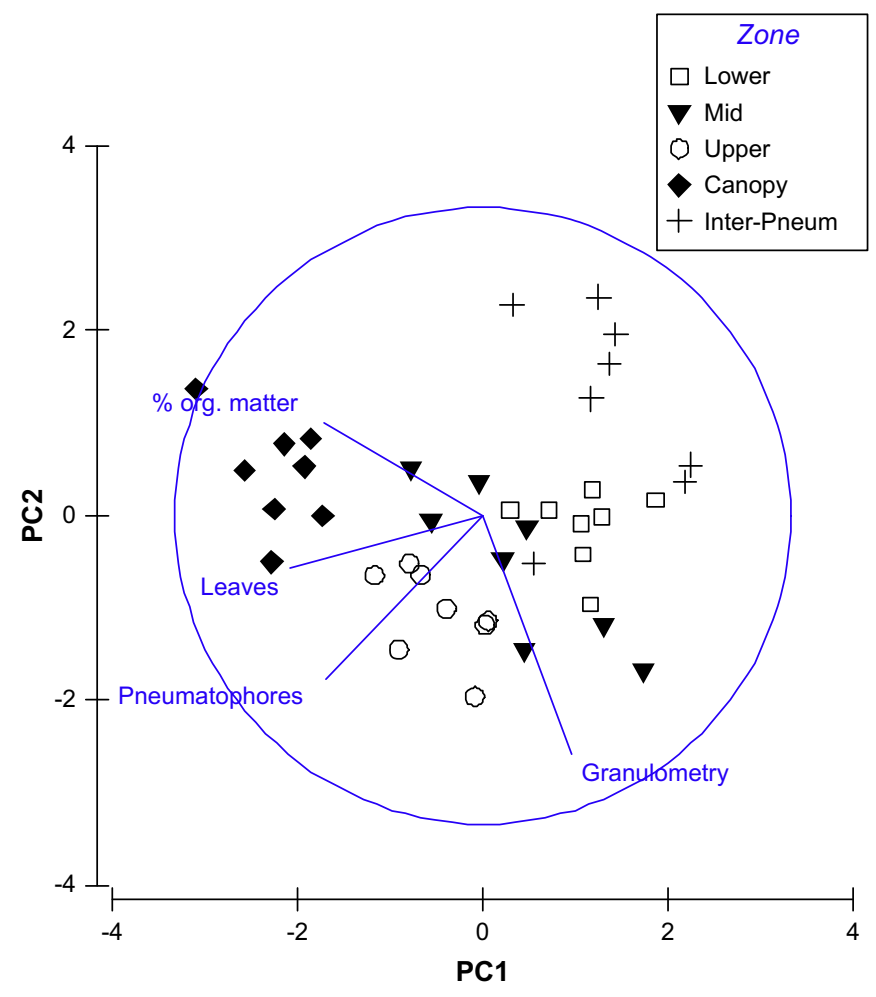

Fig. 2. Two-dimensional scatter plot of the First and Second Canonical axes for all environmental variables measured in each study zone. Variable eigenvectors for PC1 $(x$-axis) and PC2 ( $y$-axis) are, respectively, leaves $(-0.626 ;-0.173)$, pneumatophores $(-0.510 ;-0.528)$, organic content $(-0.516 ; 0.304)$, and average grain size $(0.285$; -0.774 ) (see text for further explanation).

BEST analysis indicated that $85.5 \%$ of the Terebralia palustris abundance can be explained by only two environmental variables: sediment organic content and the abundance of leaves, with the former accounting for $\sim 80 \%$ of the variation. Granulometry and the density of leaves and pneumatophores account for $\sim 65 \%$ of the gastropod size distribution, with the pneumatophore density explaining slightly more than $45 \%$ of this distribution.

\section{Discussion}

\subsection{Microhabitat characterization}

The environmental variables covered in this study were found to gradually change from Lower and Inter-pneumatophore zones towards the Canopy. The more congested the mangrove root systems (towards the Canopy) the more effective they become as litter traps, increasing the organic content of the soil, and also trap smaller sediment particles, creating a more muddy sediment (Robertson and Alongi, 1992; Hogarth, 2007). This further increases the organic content as finer particles have a larger surface area for the adsorption of organic matter. The Inter-pneumatophore zone had almost no pneumatophores and very sandy sediments. However, the leaf density was also as high as the Mid zone, where pneumatophore density was much higher. This may be due to the fact that the Inter-pneumatophore zones is located between the Upper and Canopy zones, both of these generating considerable leaf litter, and the Inter-pneumatophore zone is a passive corridor that exports mangrove litter (supported by the depleted $\delta^{13} \mathrm{C}$ values measured in sediment in this zone).

With regard to the stable isotopic analyses, all the mangrove leaves had similar $\mathrm{C}$ and $\mathrm{N}$ isotopic signatures when compared to 


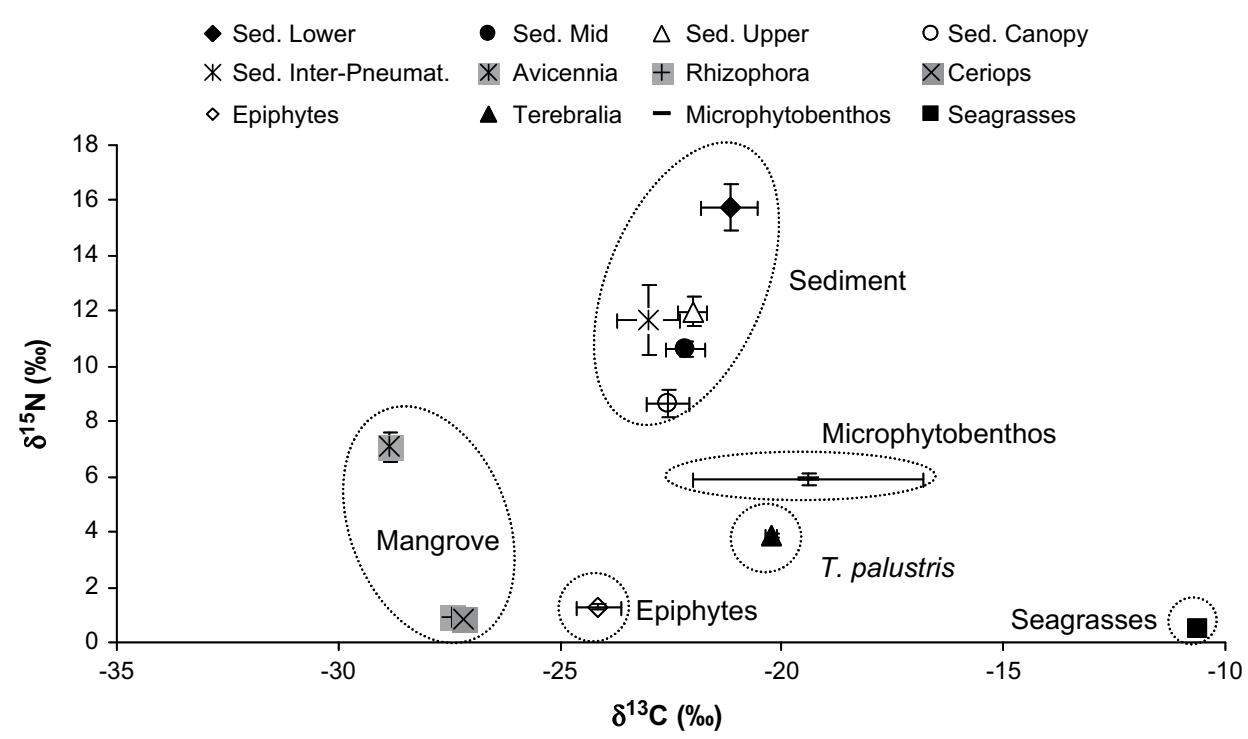

Fig. 3. Plot of average $\delta^{13} \mathrm{C}$ and $\delta^{15} \mathrm{~N}$ values in Terebralia palustris foot muscle, sediment and primary producers in the study area. Microphytobenthos data were obtained from previous studies in Saco Bay, Inhaca, Mozambique (Abreu et al., in press). Error bars indicate SE $(n=5-60)$.

previous studies undertaken in the Saco mangrove (e.g., Macia, 2004), except for the $\delta^{15} \mathrm{~N}$ values obtained for Avicennia marina leaves, which were much higher. Results obtained in the surface sediments yielded average $\delta^{13} \mathrm{C}$ values that were similar to other studies, although the $\delta^{15} \mathrm{~N}$ was, on average, much higher (8.7$15.8 \%$ ) than that found in previous studies (1.0-4.0\%) (e.g., Bouillon et al., 2002, 2004; Macia, 2004). Previous literature has already recorded high $\delta^{15} \mathrm{~N}$ signatures for $A$. marina leaves as well as for mangrove surface sediment (for a review see Bouillon et al., 2008). The high values and variability of the $\delta^{15} \mathrm{~N}$ signatures are likely to be due to a difference in nitrogen processes in the sediments of the different zones. Also, during sampling, runoff water from a nearby village was regularly observed, which could be a source of isotopically enriched nitrogen (Bouillon et al., 2008).

Due to difficulties in sampling, $\delta^{13} \mathrm{C}$ data for seagrasses and benthic microalgae were obtained from previous studies (Abreu et al., in press). These data provide a clear distinction between the $\delta^{13} \mathrm{C}$ signatures of mangrove tissues (approximately $-28 \%$ ) compared to the other carbon sources available in the area, i.e. epiphytes $(-23.7 \%$ ), benthic microalgae $(-19.4 \%$ ) and seagrass $(-11.9 \%)$ detritus.

\subsection{Population structure microdistribution and feeding preferences}

The spatial segregation between juveniles and adults of Terebralia palustris reported by various authors for Jakarta (Soemodihardjo and Kastoro, 1977), Western Australia (Wells, 1980) and Gazi Bay, Kenya (Slim et al., 1997; Pape et al., 2008) was also encountered

\section{Table 3}

Average $( \pm \mathrm{SD}) \delta^{13} \mathrm{C}(\%)$ and $\delta^{15} \mathrm{~N}(\%)$ and $\mathrm{C} / \mathrm{N}$ ratios obtained for sediment samples from different zones. Different letters indicate significant difference $-p<0.05-$ between the five zones $(n=6)$.

\begin{tabular}{lcll}
\hline Zone & \multicolumn{2}{l}{ Stable isotopes } & C/N ratio \\
\cline { 2 - 3 } & $\delta^{15} \mathrm{~N}$ & $\delta^{13} \mathrm{C}$ & \\
\hline Inter-pneumatophore & $11.7 \pm 2.9^{\mathrm{a}, \mathrm{b}}$ & $-23.0 \pm 1.6$ & $18.8 \pm 2.0^{\mathrm{a}}$ \\
Lower & $15.8 \pm 2.0^{\mathrm{a}}$ & $-21.2 \pm 1.6$ & $13.6 \pm 1.3^{\mathrm{b}}$ \\
Mid & $10.6 \pm 0.7^{\mathrm{b}}$ & $-22.2 \pm 1.1$ & $14.5 \pm 1.0^{\mathrm{b}}$ \\
Upper & $12.0 \pm 1.2^{\mathrm{a}, \mathrm{b}}$ & $-22.0 \pm 0.8$ & $14.5 \pm 0.8^{\mathrm{b}}$ \\
Canopy & $8.7 \pm 1.3^{\mathrm{b}}$ & $-22.6 \pm 1.2$ & $13.7 \pm 1.2^{\mathrm{b}}$ \\
\hline
\end{tabular}

in the present study. Small T. palustris were more common on lower, open sandflats, while larger individuals tended to reside inside the mangrove forest. Both previous studies (Slim et al., 1997; Pape et al., 2008) suggested that $5 \mathrm{~cm}$ was the critical size at which $\delta^{13} \mathrm{C}$ decreased, indicating an increase in leaf consumption, most likely caused by an ontogenetic change in diet (Houbrik, 1991). However, it should be stressed that in the Saco, the T. palustris population attained a maximum height of $6.25 \mathrm{~cm}$. The clear decrease in $\delta^{13} \mathrm{C}$ values in individuals measuring more than $5 \mathrm{~cm}$ in height is in agreement with previous research undertaken in Ceriops tagal (Slim et al., 1997) and Sonneratia alba (Pape et al., 2008) mangrove forests where gastropods reach much larger shell sizes.

Small Terebralia palustris were characterized by an average stable carbon isotope value of $-20.1 \%$ w which was $2.1 \%$ enriched relative to their suggested main food source (sediment, with a $\delta^{13} \mathrm{C}$ average value of $-22.2 \%$ ). Although a general increase of $0-1 \%$ could partially explain the observed discrepancy (Bouillon et al., 2008), selective assimilation of microbenthic algae could be taking place, as suggested by Pape et al. (2008). Microbenthic algae in the Saco displayed an average $\delta^{13} \mathrm{C}$ value of $-19.4 \%$ (Abreu et al., in press), a value similar to the one we obtained for smaller T. palustris. The high nutritional value of microalgae compared to mangrove tissue may also explain the higher densities of smaller gastropods in the lower intertidal zones, since the microalgal biomass in the upper zones is probably lower due to the lower light intensity under the dense canopy and inhibition caused by soluble tannins released by mangrove leaves (Alongi and Sasekumar, 1992). On the other hand, $\delta^{13} \mathrm{C}$ signatures of larger T. palustris all fell in a narrow range between -21 and $-22 \%$, which is still $\sim 6.0 \%$ onriched relative to their apparent food source, namely Avicennia marina leaves $\left(\delta^{13} \mathrm{C}\right.$ value of $-28.8 \%$ ), which accounted for more than $90 \%$ of the total number of leaves found in litter in the study area (personal observation). The large difference in carbon isotope signatures between larger snails and A. marina mangrove leaves suggests that other food sources contributed the bulk of their diet. In this study, larger individuals were also observed to actively feed on pneumatophore epiphytes and graze the surface sediments. Both these carbon sources would provide the more enriched values of $\delta^{13} \mathrm{C}$ observed. These findings thus suggest that leaves may not be the most important diet of these gastropods and, although they are known to consume a large amount of leaf material (Fratini et al., 
Table 4

Average $( \pm \mathrm{SD}) \delta^{13} \mathrm{C}(\%)$ and $\delta^{15} \mathrm{~N}(\%)$ of foot muscle of $T$. palustris for different size classes and zones. Different letters indicate significant difference $-p<0.05-$ between the zones. Number in parenthesis indicates number of replicates (n.a. - not available).

\begin{tabular}{|c|c|c|c|c|c|c|c|c|}
\hline \multirow[t]{2}{*}{ Size classes $(\mathrm{cm})$} & \multicolumn{4}{|l|}{$\delta^{13} \mathrm{C}$ stable isotope $(\%)$} & \multicolumn{4}{|l|}{$\delta^{15} \mathrm{~N}$ stable isotope $(\%)$} \\
\hline & Inter-pneumatophore & Mid & Upper & Canopy & Inter-pneumatophore & Mid & Upper & Canopy \\
\hline$x<3$ & $-19.4 \pm 0.6^{\mathrm{a}}(8)$ & $-20.9 \pm 0.4^{\mathrm{b}}(7)$ & $-20.0 \pm 0.5^{\mathrm{a}}(8)$ & n.a. & $3.9 \pm 0.2^{\mathrm{a}}(8)$ & $3.7 \pm 0.2^{\mathrm{a}}(7)$ & $2.9 \pm 0.2^{b}(8)$ & n.a. \\
\hline $3<x<5$ & $-18.9 \pm 0.7^{\mathrm{a}}(8)$ & $-20.3 \pm 0.6^{\mathrm{b}}(9)$ & $-20.5 \pm 0.8^{b}(5)$ & $-19.9 \pm 0.3^{\mathrm{a}, \mathrm{b}}(4)$ & $4.6 \pm 0.4^{\mathrm{a}}(8)$ & $4.3 \pm 0.3^{\mathrm{a}, \mathrm{b}}(9)$ & $4.1 \pm 0.2^{\mathrm{a}, \mathrm{b}}(5)$ & $4.0 \pm 0.1^{b}(4)$ \\
\hline$x>5$ & $-21.2(1)$ & $-21.1 \pm 0.8(2)$ & $-21.0 \pm 1.0(7)$ & $-22.0 \pm 0.8(4)$ & $4.0(1)$ & $3.9 \pm 0.2(2)$ & $3.7 \pm 0.3(7)$ & $3.7 \pm 0.5(4)$ \\
\hline
\end{tabular}

2004), other food sources merit consideration in global carbon budgets in mangrove habitats. This is especially true of small gastropods that may represent a significant percentage of the T. palustris biomass, as in the present study. Despite the potentially large-scale movement of organic matter, the significant differences found between gastropods inhabiting the different zones indicate that they obtain their nutrition variably from the local sediment, leaves and epiphytes. This has been illustrated by Guest et al. (2004) for crabs and other gastropod species inhabiting the perimeter of saltmarshes and mangrove forests. However, it must also be recognized that the $\delta^{13} \mathrm{C}$ and $\delta^{15} \mathrm{~N}$ in the animals they studied is not only a reflection of their food source at the time of sampling, but also results from the diet consumed during the preceding period (McCutchan et al., 2003).

Previous studies have demonstrated that the density of these gastropods is strongly correlated to grain size and organic content (e.g., Wells, 1980; Rambabu et al., 1987; Fratini et al., 2004), while others have found no such relationship (Pape et al., 2008). Results of our study indicate that the environmental parameter that best explained Terebralia palustris distribution and density (higher than $85 \%$ ) is the sediment organic matter content, followed by the abundance of leaves. This correlation seems reasonable since a higher availability of food resources usually positively affects the invertebrate biomass inhabiting a particular microhabitat.

The environmental variables that better explained Terebralia palustris population size structure distribution (more than 65\%) were grain size, and the number of leaves and pneumatophores, with the latter (pneumatophores) accounting for more than $45 \%$ of this distribution. The higher the density of pneumatophores, the finer the sediment and the greater the abundance of leaves, leads to a larger animal size in any particular zone. According to our stable isotope analyses, a higher concentration of organic detritus and microalgae would promote higher densities of smaller individuals, while a high density of mangrove leaves would lead to a greater abundance of larger individuals. However, if we focused only on organic matter content and leaf density, we would be unable to explain more than $40 \%$ of the T. palustris population structure microdistribution.

The absence of juvenile gastropods from muddier sediments in the mangrove forest was observed in earlier studies, and was

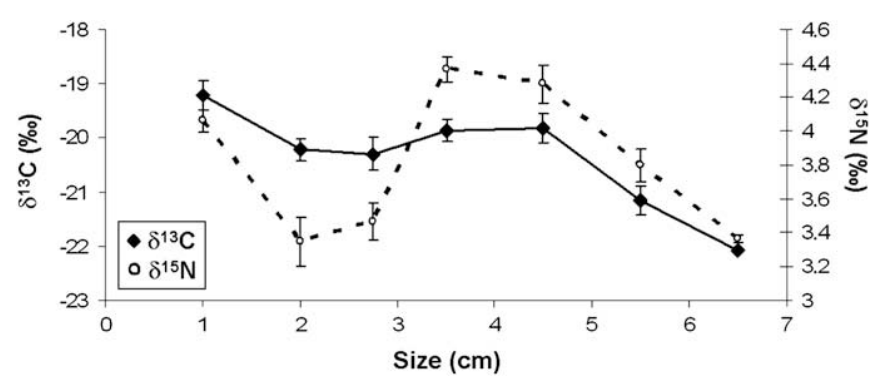

Fig. 4. Changes in $\delta^{15} \mathrm{~N}$ and $\delta^{13} \mathrm{C}$ (average $\pm \mathrm{SE}$ ) in T. palustris foot muscle with increasing shell height in the study area. attributed to the finer sediment and the associated biogeochemical properties, such as high salinity (Pape et al., 2008). It is also known that smaller individuals have a larger surface/volume ratio, decreasing their resistance to desiccation, and may occupy lower zones that provide a longer immersion period, as well as benefiting them with more or less continuous runoff from the upper zones during low tide (personal observation). Although this seems to indicate the existence of an "ontogenic migration" from the Interpneumatophore zone to the Mid pneumatophore zone, after which the animals migrate towards the Canopy zone, this was not proven in this study and other reasons may also merit consideration. Differences in recruitment, growth, mortality and predation, as well as intra-specific competition for space or resources, may also be contributors in this regard.

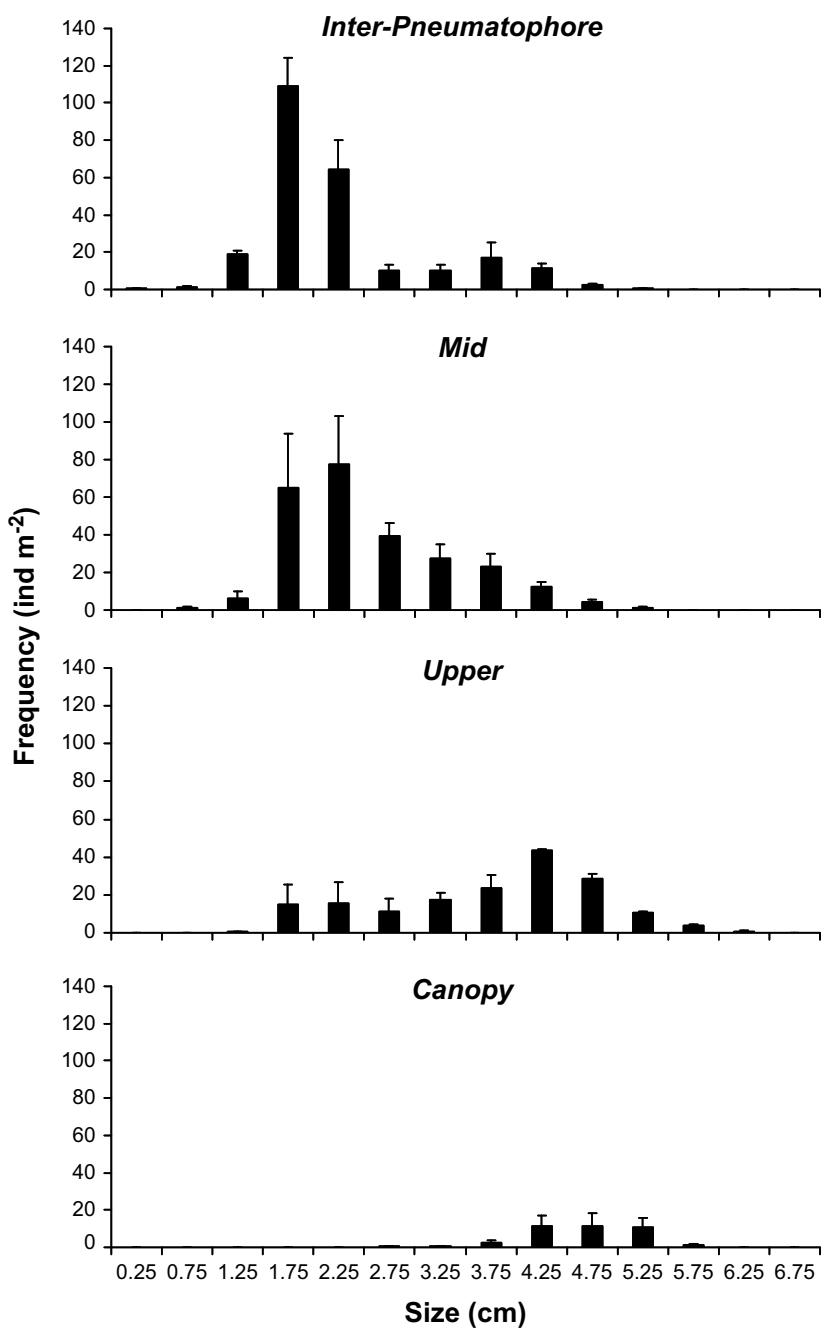

Fig. 5. Size frequency distribution of T. palustris (avg \pm SE) in the four (Mid, Upper, CANOPY and Inter-pneumatophore) Avicennia marina zones. The Lower zone is not shown due to the very low density of the individuals encountered. 


\section{Conclusion}

Stable isotope signatures suggest that smaller Terebralia palustris feed on sediment and benthic microalgae, while larger individuals feed on sediment, epiphytes and mangrove leaves. This further suggests that the population structure and distribution of T. palustris are correlated with environmental factors within the different microhabitats. While the organic content seems to better correlate with the density of $T$. palustris, gastropod size distribution correlates best with the number of pneumatophores. Young T. palustris (height $<3 \mathrm{~cm}$ ) occur predominantly in lower intertidal microhabitats characterized by a reduced number of leaves and pneumatophores, reduced organic matter content and large sediment grain sizes. As they grow larger, T. palustris are found closer to the mangrove tree microhabitats characterized by a higher density of pneumatophores and litter, as well as smaller sediment grain sizes, providing richer organic matter.

\section{Acknowledgements}

The authors would like to thank João Fereira and Michel Korntheuer for help in data collection and analysis. Also helpful were the comments by Ana Queirós and Paulo Torres. G.P.-L. thanks Fundação para a Ciência e a Tecnologia (scholarship SFRH/BD/25277/ 2005) for supporting his Ph.D. Authors would like to thank the European Union Research Project PUMPSEA (INCO-CT2004510863) for financial support.

\section{References}

Abreu, D., Paula, J., Macia, Jr., A., Connectivity between tropical coastal habitats: using stable isotopes in juvenile penaeid shrimps and potential food sources. Marine Biology, in press.

Alongi, D.M., Sasekumar, A., 1992. Benthic communities. Tropical Mangrove Ecosystems, 137-171.

Bandeira, S.O., 1995. Marine botanical communities of Southern Mozambique: seagrass and seaweed diversity and conservation. Ambio 24, 506-509.

Blott, S.J., Pye, K., 2001. Gradistat: a grain size distribution and statistics package for the analysis of unconsolidated sediments. Earth Surface Processes and Landforms 26, 1237-1248.

Bouillon, S., Koedam, N., Raman, A.V., Dehairs, F., 2002. Primary producers sustaining macro-invertebrate communities in intertidal mangrove forests. Oecologia 130, 441-448.

Bouillon, S., Moens, T., Overmeer, I., Koedam, N., Dehairs, F., 2004. Resource utilization patterns of epifauna from mangrove forests with contrasting inputs of local versus imported organic matter. Marine Ecology Progress Series 278, 77-88.

Bouillon, S., Connolly, R.M., Lee, S.Y., 2008. Organic matter exchange and cycling in mangrove ecosystems: recent insights from stable isotope studies. Journal of Sea Research 59, 44-58.

Chapman, M.G., Tolhurst, T.J., 2007. Relationships between benthic macrofauna and biogeochemical properties of sediment at different spatial scales and among different habitats in mangrove forests. Journal of Experimental Marine Biology and Ecology 343, 96-109.

Clarke, K.R., Gorley, R.N., 2006. PRIMER v6: User Manual/Tutorial. PRIMER-E, Plymouth UK, 192 pp.
Dahdouh-Guebas, F., Verneirt, M., Tack, J.F., Van Speybroeck, D., Koedam, N., 1998. Propagule predators in Kenyan mangroves and their possible effect on regeneration. Marine and Freshwater Research 49, 345-350.

De Boer, W.F., 2000. Biomass dynamics of seagrass photosynthesis, growth and seagrass vegetation as different nutrient sources for an intertidal ecosystem in Mozambique. Aquatic Botany 66, 225-239.

Dehairs, F., Rao, R.G., Chandra Mohan, P., Raman, V., Marguillier, S., Hellings, L., 2000. Tracing mangrove carbon in suspended matter and aquatic fauna of the Gautami-Godavari Delta, Bay of Bengal (India). Hydrobiologia 431, 225-241.

Folk, R.L., 1954. The distinction between grain size and mineral composition in sedimentary rock nomenclature. Journal of Geology 62, 344-359.

Fratini, S., Cannicci, S., Vannini, M., 2000. Competition and interaction between Neosarmatium smithi (Crustacea: Grapsidae) and Terebralia palustris (Mollusca: Gastropoda) in Kenyan mangroves. Marine Biology 137, 309-316.

Fratini, S., Vigiani, V., Vannini, M., Cannicci, S., 2004. Terebralia palustris (Gastropoda: Potamididae) in a Kenyan mangal: size structure, distribution and impact on the consumption of leaf litter. Marine Biology 144, 1173-1182.

Guest, M.A., Connolly, R.M., 2004. Fine-scale movement and assimilation of carbon and saltmarsh and mangrove habitats. Aquatic Ecology 38, 599-609.

Guest, M.A., Connolly, R.M., Loneragen, N.R., 2004. Carbon movement and assimilation by invertebrates in estuarine habitat at a scale of metres. Marine Ecology Progress Series 278, 27-34.

Guest, M.A., Connolly, R.M., Lee, S.Y., Loneragen, N.R., Breitfuss, M.J., 2006. Mechanism for the small-scale movement of carbon among estuarine habitats: organic matter transfer not crab movement. Oecologia 148, 88-96.

Heiri, O., Lotter, A.F., Lemcke, G., 2001. Loss on ignition as a method for estimating organic and carbonate content in sediments: reproducibility and comparability of results. Journal of Paleolimnology 25, 101-110.

Hogarth, P.J., 2007. The Biology of Mangroves and Seagrasses. Oxford University Press, New York, 273 pp.

Houbrik, R.S., 1991. Systematic review and functional morphology of the Mangrove snails Terebralia and Telescopium (Potamididae; Prosobranchia). Malacologia 33, 289-338.

Kalk, M., 1995. A Natural History of Inhaca Island. Witwatersrand University Press, Johannesburg, $395 \mathrm{pp}$.

Macia, A., 2004. Primary carbon sources for juvenile penaeid shrimps in a mangrove-fringed Bay of Inhaca Island, Mozambique: a dual carbon and nitrogen isotope analysis. Western Indian Ocean Journal of Marine Science 3, 151-161.

McCutchan, J.H., Lewis, W.M., Kendall, C., McGrath, C.C., 2003. Variation in trophic shift for stable isotope ratios of carbon, nitrogen, and sulfur. Oikos 102, 378-390.

Nishihira, M., 1983. Grazing of the mangrove litters by Terebralia palustris (Gastropoda: Potamididae) in the Okinawan mangal: preliminary report. Galaxea 2, 45-48.

Pape, E., Muthumbi, A., Kamanu, C.P., Vanreusel, A., 2008. Size-dependent distribution and feeding habits of Terebralia palustris in mangrove habitats of Gazi Bay, Kenya. Estuarine, Coastal and Shelf Science 76, 797-808.

Rambabu, A.V.S., Prasad, B.V., Rao, M.B., 1987. Response of the mangrove mudsnail Terebralia palustris (Linnaeus) (Prosobranchia: Potamididae) to different substrata. Journal of Marine Biological Association of India 29, 140-143.

Robertson, A.I., Alongi, D.M., 1992. Tropical mangrove ecosystems. In: Coastal and Estuarine Studies, vol. 41. American Geophysical Union, Washington, 332 pp.

Slim, F.J., Hemminga, M.A., Ochieng, C., Jannink, N.T., Cocheret de la Morinière, E., Van der Velde, G., 1997. Leaf litter removal by the snail Terebralia palustris (Linneaus) and sesarmid crabs in an East African mangrove forest (Gazi Bay, Kenya). Journal of Experimental Marine Biology and Ecology 215, 35-48.

Soemodihardjo, A., Kastoro, W., 1977. Notes on the Terebralia palustris (Gastropoda) from the coral islands in the Jakarta Bay area. Marine Research in Indonesia 18, 131-148.

Wells, F.E., 1980. A comparative study of the mudwhelks Terebralia sulcata and $T$. palustris in a mangrove swamp in northwestern Australia. Malacological Review 13, 1-5.

Zieman, J.C., Macko, S.A., Mills, L., 1984. Role of seagrasses and mangroves in estuarine food webs: temporal and spatial changes in stable isotope composition and amino acid content during decomposition. Bulletin of Marine Sciences 35, 380-392. 